\title{
«THE LADY OF THE HOUSE OF LOVE» Y «THE SCARLET HOUSE» DE ANGELA CARTER: EL CONOCIMIENTO HISTÓRICO Y LA CAVERNA DE PLATÓN
}

\author{
«THE LADY OF THE HOUSE OF LOVE» AND «THE SCARLET HOUSE» BY \\ ANGELA CARTER: HISTORICAL KNOWLEDGE AND PLATO'S CAVE
}

\author{
Emilio José Álvarez Castaño \\ Shandong University \\ telemilio@yahoo.es
}

Fecha de recepción: 02-11-2020

Fecha de aceptación: 29-01-2021

\section{RESUMEN}

La obra de Angela Carter ha sido estudiada habitualmente desde el feminismo y el postmodernismo. Sin negar este hecho, el presente artículo quiere destacar la importancia de la Historia en la obra de Carter centrándose en el análisis de sus relatos «The Lady of the House of Love» y «The Scarlet House». Las ideas que tenía Carter al respecto, enmarcadas muchas de ellas en la postmodernidad, pueden encontrar acomodo en diferentes aproximaciones dentro de la filosofía de la Historia, lo que permitiría una interpretación en clave histórica de estas dos narraciones, un hecho que la propia Carter admite al aceptar la multiplicidad de lecturas en una obra literaria. Puesto que las protagonistas de ambos relatos están confinadas en espacios que desean abandonar, se destaca en dicho contexto la relevancia de la caverna de Platón.

Palabras Clave: «The Lady of the House of Love»; «The Scarlet House»; Angela Carter; filosofía de la historia; memoria; palimpsesto; caverna de Platón

\section{AbSTRACT}

Angela Carter's work has been usually studied from the perspective of feminism and postmodernism. Without denying this fact, this paper wants to underline the importance of 
History in Angela Carter's work focusing on the analysis of her short stories «The Lady of the House of Love» and «The Scarlet House». Carter's ideas on this issue, most of them framed in postmodernity, can find a suitable place among different approaches within the philosophy of History, something which will allow a historical reading of these two short stories. This type of interpretation was admitted by Carter herself when she accepted the multiplicity of readings for the same literary work. Since the protagonists of both stories are confined to spaces they wish to abandon, the relevance of Plato's cave stands out in this context.

Keywords: «The Lady of the House of Love»; «The Scarlet House»; Angela Carter; philosophy of history; memory; palimpsest; Plato's cave

\section{INTRODUCCIÓN}

En la producción literaria de Angela Carter (1940-1992) descuellan dos aspectos que han sido señalados repetidas veces en diversos estudios que se han hecho sobre su obra, como son el feminismo y la reescritura que hizo sobre algunos cuentos de hadas y cuentos folklóricos, aunque también se han destacado y analizado otros rasgos y elementos como el circo, las marionetas, el vampirismo (BOTELHO, 2016: 293), la casa, la parodia, lo gótico (PÉREZ GIL, 1996: 96 y ss.). Sin negar la relevancia de este hecho, el presente estudio pretende resaltar la importancia del fenómeno histórico en diferentes obras de la citada escritora inglesa como preámbulo a una propuesta de lectura en clave histórica de sus relatos «The Lady of the House of Love» $y$ «The Scarlet House». Se trata de unas narraciones que, como otras muchas obras de Carter, admiten una interpretación de tipo feminista. Desde estas líneas se defenderá la pertinencia de una lectura histórica puesto que ayudará a resaltar la importancia de este acercamiento en la obra de Angela Carter dentro del contexto postmoderno en el que se sitúa la autora. Para ello, se comentará la presencia y el punto de vista que tiene la Historia en destacadas obras de Angela Carter. Después, se entrará en el análisis de cada una de las obras desde esta perspectiva histórica. Se continuará con una propuesta de identificación de las distintas ideas que Angela Carter tenía sobre este campo con diversas teorías dentro de la filosofía de la Historia, donde cobra un papel relevante la metahistoria. El lugar en el que se desarrolla la acción en ambos relatos y este descubrimiento metahistórico son vinculables con la caverna de Platón en tanto que supone una alegoría del conocimiento que también buscará una toma de postura al respecto por parte del lector.

\section{LA HISTORIA EN ANGELA CARTER}

La importancia que cobra la Historia en la obra de Angela Carter se puede encuadrar dentro del marco teórico que describió Bonnie Smith (1998), en el que hizo ver la labor historiográfica realizada por mujeres y de qué manera quedó silenciada por la oficialidad andrógina. Considerando esto, el presente apartado se centra en comentar cuatro aspectos que muestran ejemplos de la presencia de la Historia en la obra de Carter: la Historia y los grupos marginales, la difusa frontera entre Historia y ficción, la Historia como palimpsesto y, 
en último lugar, la memoria. En todos ellos se verá de qué manera Carter se muestra como una escritora que enmarca sus ideas en el momento histórico y cultural que vivió.

El interés que tenía Angela Carter por la Historia no está presente solo en su faceta creativa, como se verá, sino que también se pueden encontrar reflexiones al respecto en su obra ensayística. En 1971 publicó The Sadeian Woman, subtitulado An Exercise in Cultural History, que comienza de la siguiente forma:

Pornographers are the enemies of women only because our contemporary ideology of pornography does not encompass the possibility of change, as if we were the slaves of history and not its masters, as if sexual relations were not the result of social relations, as if sex itself were an external fact, one as immutable as the weather, creating human practice but never part of it. (2001: 3-4)

Donde, dentro de la idea feminista que reivindica, pone en valor el papel de las mujeres a lo largo de la Historia. Se trata de una idea que tiene su ampliación en aquellos postulados teóricos que sostienen que esta disciplina debe atender a aquellas personas que han sido olvidadas o peor tratadas de manera habitual, porque la construyen todas las personas y no se debe contemplar como una relación de dominio de un grupo sobre otro.

Esta idea tiene su prolongación en los textos de ficción. Dentro de su faceta como editora de cuentos de hadas, en la introducción de su Book of Fairy Tales que, en 2005, recogía los dos volúmenes que publicó con anterioridad, Carter señalaba que la historia, la sociología y la psicología que contemplaban estas narraciones era siempre la no oficial (2005: xii). Se trata, por tanto, de una defensa de aquellos campos que, de manera habitual, no son recogidos por la historiografía.

Ya como novelista, Nights at the Circus (1984) se encuadra en lo que Linda Hutcheon llamó la «historiographic metafiction», cuyos protagonistas «are the ex-centrics, the marginalized, the peripheral figures of fictional history» (2004: 113-114), una idea sobre la que vuelve a reflexionar en Wise Children (1991), una obra que se ha llegado a definir de la siguiente forma:

[A]s a text that deals with the histories of those who have been oppressed in society rather than a single true «History» with a capital H. Instead of depicting men's or rulers' history, Dora focuses on the lives of the poor and working-class women as well as on the so-called «low» cultures, from music halls to TV shows. (OKUHATA, 2019: 264)

Se trata de una novela en la que Shakespeare es utilizado como el paradigma de lo que se estima ahora como Arte o Cultura, entendiendo ambos términos en su ámbito oficial, en comparación con otras manifestaciones artísticas que no gozan de la misma consideración. De hecho, en la familia protagonista, cuyos miembros se dedican al mundo del espectáculo, las gemelas Dora y Nora Chance, que son hijas naturales de Melchior Hazard, son coristas, mientras que los hijos reconocidos del mismo padre se dedican a la televisión.

Pero este hecho no quiere decir que no se le deba prestar la oportuna atención a estas personas y elementos, algo que está en relación, y forma parte ya del segundo aspecto a comentar, de la desconsideración que han recibido dentro de la narrativa lo que Barthes llamó 
«residuos» pero que, gracias al detalle y al grado de minuciosidad que pueden alcanzar, se presentan como parte indispensable para lograr el llamado «efecto de realidad», de ahí que el filósofo francés llegara a la conclusión de que el discurso histórico y la prosa de ficción presenten el mismo grado de credibilidad (VLITOS, 2017: 1400-1401). En la producción de Angela Carter, el relato «The Fall River Axe Murders», publicado dentro de su obra Black Venus (1985), explora y comprueba la línea que divide la prosa de ficción del discurso histórico y utiliza de manera repetida el recurso de los olores para caracterizar fidedignamente una época pasada. La irresolución de lo acontecido en el conocido caso de los asesinatos en casa de Lizzie Borden y las diferentes versiones que se dieron al respecto supusieron un material ideal para que Carter reflexionara sobre dónde radica la realidad de los hechos históricos dentro de su concepción literaria postmoderna. Se trata de una idea que ya tenía en mente dos años antes, en 1983, cuando publicó «Extracts from a Work-in-progress Entitled: The Fall River Axe Murders», un ensayo que incluía escenas de la vida familiar de los Borden y que diferiría mínimamente de su posterior relato, aunque la versión que apareció en Saints and Strangers, título con el que se publicó Black Venus en Estados Unidos, sí incorporaba algunos párrafos de esta obra donde desafía los límites entre ficción y no ficción, entre cuento y ensayo. Además, ese mismo año, llegó a afirmar en «Notes from the Front Line»: «I try, when I write fiction, to [...] present a number of propositions in a variety of different ways, and to leave the reader to construct her own fiction from the elements of my fictions» (2013: 45). En el caso del citado relato, al ofrecer distintas narraciones sobre los mismos hechos, Carter procuraba poner al lector en el lugar de un investigador ante un archivo histórico para que acabara cuestionándose sobre la validez del término real cuando se estudia el pasado histórico (RICOEUR, 1988: 142), por no decir que documenta la desaparición del conocimiento histórico (BERNI, 1997: 49). Carter se burla del intento por alcanzar la objetividad histórica cuando, en el relato, enumera de forma exagerada e irónica las posibles causas del asesinato. Al admitir la imposibilidad de alcanzar la verdad histórica, Carter coincide al mismo tiempo con aquella observación de Jameson según la cual la Historia es inaccesible a menos que se haga de una manera textual (2002: 67). Por este motivo, se ha llegado a apuntar que, en esta versión sobre lo sucedido a la familia Borden, Carter sugiere que Lizzie construye su realidad basándola en las realidades emocionales de los cuentos de hadas (BERNI, 1997: 52), y que la forma en la que se produce la Historia es por medio de un catálogo de conocimientos recibidos donde se mezclan narraciones históricas y ficticias (1997: 53). Más adelante se comentarán más detalles sobre este aspecto.

Por tanto, se puede dar el caso de que a la escritura de unos hechos le sucedan diferentes reescrituras y versiones, que en ocasiones pueden presentarse superpuestas. En la obra de Angela Carter, como se ha indicado, se pueden encontrar narraciones donde se mezclan rasgos de los cuentos de hadas y folklóricos, la pornografía, la mitología, la picaresca, entre otras obras. Un ejemplo al respecto se tiene en el relato «The Bloody Chamber» (1979), del que se ha documentado suficientemente su riqueza alusiva para, a partir de ahí, alabar cómo esta cualidad del texto como palimpsesto tiene una importante función pedagógica por la que enseña al lector a descifrar aquellos significados que todavía se encuentran ocultos (HENNARD, 2013: 111). Por ello, en líneas generales, se ha afirmado que la escritura de Angela Carter es un palimpsesto de significados donde cada interpretación puede dar paso a la siguiente (Filimon, 2014: 176). Desiderio, el protagonista de The Infernal Desire Machines of Doctor Hoffman (1972), tiene que 
elegir entre la realidad y sus deseos y acaba considerado como un héroe de guerra por la Historia pero, en toda la narración en primera persona, Carter apunta de manera repetida a una serie de hechos que no tienen un seguimiento completo en el texto, con lo que el lector puede vincular esta situación con la que él está viviendo al verse influenciado de manera constante por las distintas versiones de la realidad que proporcionan los medios de comunicación, que afectan no solo a sus ideas y creencias sino también a sus emociones.

No obstante, todas estas ideas y afirmaciones carecerían de sentido sin el papel que desempeña la memoria en la construcción del discurso histórico. En Heroes and Villains (1969) hay un claro discurso feminista que surge frente a conceptos patriarcales, pero también se destaca la importancia de la memoria de cara al futuro en un mundo postapocalíptico. Por eso se ha afirmado:

It is certain that «history», to some extent, can remain in the written texts or records protected in the archives in the Professors' village, and the three groups might survive as «living corpses», even after the extinction of civilization. However, there will be no evolution or development for the people who have forgotten the nuclear war, or their «Original Sin» in the past. (OKUHATA, 2019: 143)

En plena Guerra Fría, Carter lanza esta advertencia que señala el fin de la Historia no como la extinción de la raza humana sino como el fin de una idea de civilización en un momento en el que los seres humanos seguían sin ser conscientes de las consecuencias de una conflagración nuclear. Por tanto, solo la mirada al pasado por medio de la memoria ayudaría a un nuevo comienzo.

La memoria se presenta como un elemento de importancia capital en «The Scarlet House». Es el elemento que el Conde quiere eliminar porque es la principal diferencia entre el ser humano y las bestias (CARTER, 2006b: 418). Frente al mundo de la casa en la que se encuentra recluida, la protagonista mantiene memorias familiares, como la foto de su madre, el recuerdo del parecido de los ojos de ambas y el padre reconstruyendo la tetera rota a partir de los diferentes pedazos, como se trata de reconstruir el pasado a partir de los trozos de memoria que se conservan. Cuando se percata de la imposibilidad de apelar a la memoria, la protagonista trata de recordar a partir del inconsciente. En la narración, el inconsciente es simbolizado en el halcón, como la pista de la memoria que la narradora tiene de su captura, preservado como una imagen, un icono. Siguiendo a Foucault, Carter apunta a que no es lo social y su imaginario colectivo lo que es terrible y peligroso sino el poder de este y la elección ético-política que se debe tomar cada día la que puede determinar dicho peligro (SEMPRUCH, 2008: 78). Y como la memoria es selectiva y, además, puede estar deformada, la narradora busca orientación en aquellos conocimientos que ya tiene adquiridos en ciertos campos, como se verá en el cuarto apartado del presente estudio.

\section{3. «THE LADY OF THE HOUSE OF LOVE»: EL CAMINO PROPIO}

«The Lady of the House of Love», publicado por primera vez en 1975 en The Iowa Review, es uno de los relatos que forman parte de The Bloody Chamber (1979), obra en la que 
Angela Carter agrupó unas narraciones basadas en conocidos cuentos de hadas con la particularidad de que las heroínas de Carter toman la iniciativa para darle la vuelta al patrón original. Esta narración en concreto está inspirada, entre otros textos, en «La bella durmiente», con el añadido de la ambientación gótica. Así, el personaje supuestamente malvado es el femenino, que es una vampira de Transilvania que necesita hombres de los que alimentarse. El personaje masculino, un joven soldado inglés presentado irónicamente como héroe y él mismo admitiendo dicha consideración (2006a: 205), aparece como la víctima inocente. En su encuentro, los dos tratan de seducir al otro pero por motivos diferentes. La atracción que él siente por su anfitriona es ambigua, debido a su belleza decadente, algo que se muestra en el rechazo a la propuesta por parte de su coronel de tener relaciones necrófilas en un burdel de París que este le recomienda. Resulta irónico, entonces, que llegue a la conclusión de que no quiera aprovecharse de ella. Por su parte, la Condesa ve en su invitado la oportunidad que estaba esperando para escapar de su reclusión pero, en su ingenuidad, el soldado no es consciente de ello ni antes de entrar en el castillo ni cuando está con ella, por eso se dice que tiene poder en potencia y que es más de lo que él sabe (2006a: 198). El gesto inocente, probablemente aprendido en su niñez, de chupar la sangre de la pequeña herida que se ha hecho la Condesa en su dedo, supone una inversión de la relación que tiene un vampiro con un humano y será el hecho desencadenante del final del relato.

«The Lady of the House of Love» se ha interpretado en numerosas ocasiones en clave feminista, como muchas otras obras de Angela Carter. Según este tipo de lectura, la Condesa muestra el rol de una mujer encerrada que debe seguir unas pautas marcadas por otros: la sociedad, la tradición, los hombres. Es de destacar aquí las miradas omniscientes que muestran los retratos de sus antepasados que, además, van evolucionando en relación al curso de los hechos que se van sucediendo. Una de esas pautas es la idea de feminidad, que se presenta como una imagen impuesta desde sistemas de representación masculinos (RODRÍGUEZ SALAS, 2008: 121). El joven, por su parte, es el héroe que tiene como misión salvarla. En esta situación, resulta lógico que la Condesa quiera romper con ese destino marcado en el que ella es la última de una saga de vampiros y que busque salir del castillo en el que se encuentra. En dicho deseo, la continua consulta a las cartas del Tarot, con el objeto de encontrar allí alguna alternativa, remite a un mismo destino que se repite continuamente: «The Tarot always shows the same configuration: always she turns up La Papesse, La Mort, La Tour Abolie, wisdom, death, dissolution» (2006a: 197). Como ocurre con los cuentos de hadas, hay que respetar una prohibición, en este caso la advertencia es que el deseo por saber más la conducirá a su destrucción. En cambio, ella sigue considerando su liberación e imagina que llegará cuando encuentre el amor pero, en realidad, este es otro pensamiento inculcado más. Cuando llega el momento de la revelación, el cuerpo de ella queda sin vida, un hecho que ha dado lugar a diferentes interpretaciones, desde las que argumentan que con ella lo que en realidad muere es una idea patriarcal (BUCHEL, 2004: 31), hasta las que sostienen que no hay muerte sino una reescritura tragicómica del mito de la vampira (PÉREZ GIL, 2016: 519). En todo caso, se trata de la forma por la que se conjuran maldiciones hereditarias, genéricas, argumentales y también aquellas marcadas por el destino, de ahí que la Condesa busque cantar su propia canción (HENNARD, 2011: 4). De igual forma, el hecho de dejar una flor también ha tenido diferentes interpretaciones, entre las que se encuentran las que apuntan a presentarla como 
emblema de la independencia femenina y de la resistencia frente a representaciones invasivas y opresivas que buscan colonizarla (BUCHEL, 2004: 32-33), a las sexuales identificándola con la vagina dentata y la idea de castración masculina (MULVEY-ROBERTS, 2016: 115).

No obstante, teniendo en cuenta la pertinencia de este tipo de lectura, cabría preguntarse sobre la posibilidad de abordar este relato desde otros presupuestos, algo a lo que la propia Angela Carter abrió la puerta dentro de su concepción literaria postmoderna. En este caso, «The Lady of the House of Love» presenta una serie de elementos que invitan a una interpretación en clave histórica. La Condesa es situada dentro del árbol genealógico de un personaje histórico como Vlad el Empalador, hay una misión familiar e histórica que ella debe continuar y, además, cronológicamente la acción se sitúa en la Primera Guerra Mundial. En este contexto, la Condesa aparece vinculada al mundo de la fantasía, al mundo del sueño en cuanto a deseos que se quieren conseguir: «In her dream, she would like to be human; but she does not know if that is possible» (2006a: 197). Y cuando, al final de la narración, toma conciencia de su nueva situación, confiesa: «I was only an invention of darkness» (2006a: 208). De manera que toda la realidad que conoce es la que ha percibido a lo largo de su vida dentro de esa peculiar torre de marfil en la que parece que se ha convertido para ella el castillo en lo que se refiere a la percepción de la realidad. El joven soldado es quien trae la imagen del mundo exterior, aparece vinculado a la lógica por medio de la bicicleta, al mundo de la razón y, debido a su situación personal, al mundo de la historia, en el que va a participar activamente. Cuando está a punto de entrar en el castillo, recuerda las historias de fantasmas que escuchaba en su niñez junto a sus hermanos, pero ahora sabe que no tiene sentido tener miedo de sus propias fantasías, es justo su ausencia de imaginación la que le da heroísmo al héroe. La Condesa y el soldado, por tanto, son personajes que pertenecen a dos ámbitos diferentes, por eso es destacable que, aunque la Condesa tenga deseos de salir del castillo, se pregunta en varias ocasiones si puede cantar su propia canción: «Can a bird sing only the song it knows or can it learn a new song?» (2006a: 195). Este camino propio tiene vinculación con la metahistoria. Cuando Hayden White desarrolló su conocida teoría no negaba a los historiadores una conceptualización propia de la historia sino que les dio elementos añadidos para que los pudieran combinar libremente (Paul 2011: 81). En este sentido, la metahistoria asume la imposibilidad de un rigor histórico total por parte de la historiografía y admite que el componente ficticio está presente desde Heródoto, a quien se aludirá más tarde. Si se acepta la idea, y la consecución, de seguir un camino propio, habría que entender que lo que muere de la Condesa es su cuerpo, pero no su espíritu, que se encontraría en un plano diferente al final del relato. En este sentido, la rosa también adquiriría una significación especial. Ya despojada de su habitual sentido simbólico amoroso, con su flor y sus espinas, la rosa aquí viene a unir la parte más atractiva, lo fantasioso, con aquello que puede resultar más desagradable, la realidad.

\section{4. «THE SCARLET HOUSE»: LOS CAMPOS EPISTEMOLÓGICOS}

El Conde de «The Scarlet House» (1977) combate cualquier intento de la protagonista por recordar, por eso la azota cuando repite que tiene los mismos ojos de su madre y ríe cuando la ve confundida, sin embargo, le da una pista cuando confiesa lo siguiente: «Man 
is an animal who insists on making patterns, says the Count contemptuously; all the world you think so highly of is nothing but pretty floral wallpaper pasted up over chaos» (2006b: 427). Justo a continuación es cuando emerge la imagen del halcón como un modelo, como un icono que busca ser una referencia en ese caos. En un relato de un contenido tan altamente alusivo como «The Scarlet House» resulta complejo mencionar todas las posibles referencias, especialmente si se tiene en cuenta la multiplicidad de lecturas que admiten muchas obras de Angela Carter, algo que ella misma incentiva y admite, como se ha comprobado. No en vano, en una entrevista publicada en enero de 1985, llegó a afirmar: «Reading a book is like re-writing it for yourself. And I think that all fiction should be open-ended. You bring to a novel, anything you read, all your experience of the world. You bring your history and you read it in your own terms» (1985: 20). Carter forma parte de una sociedad postmoderna donde no hay valores absolutos ni leyes universales sino que se depende de percepciones, de la interpretación individual. La cultura postmoderna niega un principio de estilo tradicional de unidad y pone en práctica la pluralidad, lo no concreto, la mezcla, el collage, el pastiche, (BAUMAN, 1988: 792), es decir, está constituida de trozos que se tratan de organizar siguiendo modelos de los que extraer un significado, aunque este deseo de ordenar el material conocido lleve a otro tipo de ficción. El ser humano siempre trata de sacar sentido del caos puesto que es la forma de crear una identidad (BOTELHO, 2016: 306). En este apartado se comentarán, por tanto, aquellos campos epistemológicos, modelos y estructuras que forman parte de un entramado de conocimientos previos que pueden orientar a la narradora en su situación.

En este sentido, llama la atención la presencia del mundo animal en «The Scarlet House», en muchas ocasiones atendiendo a cualidades simbólicas. Así, los zorros que se encuentran en New Bond Street son animales que, entre otras características, tienen el poder de crear espejismos (CHEVALIER y GHEERBRANT, 2007: 1090); de hecho, la narradora asegura que nunca los vio y solo dice sentir sus aullidos desde dentro de la casa. Más tarde se comprueba cómo el Conde hace que sus prisioneras acaricien un cerdo, un animal que está asociado por diferentes culturas a la glotonería (MARIÑO, 1996: 89), pero también a diversas tendencias oscuras como la gula y el egoísmo (CHEVALIER y GHEERBRANT, 2007: 275). En el relato se dice, además, que vive en la basura, con lo que aparece como el animal ideal para reflejar ese proceso de entropía que quiere introducir el Conde pero, sobre todo, porque al ser uno de los animales que devora a su propia prole es comparado con el mismo paso del tiempo. Fuera de este lugar de encarcelamiento que es la «scarlet house» aparece la mariposa, que forma parte de la alegre decoración de la casa de la protagonista, un animal habitualmente relacionado con la transformación o la resurrección, un estado que debe alcanzar dicha protagonista para salir de la situación en la que se encuentra, pero también puede apuntar a la muerte de una persona próxima (2007: 691), como así sucede con el asesinato del padre. Antes de que esto suceda, se dice que el padre ha reconstruido una tetera que se había roto y que esta tiene el cuello de un cisne, animal vinculado a la epifanía o revelación (2007: 306), que también necesita la protagonista para alcanzar la citada transformación. No obstante, los animales no se emplean con esta única función. De Madame Schreck se dice que come pájaros pequeños como «fig-peckers and thrushes» y fetos de conejos (CARTER, 2006b: 419), y el Conde aparece en un póster propagandístico cabalgando sobre una serpiente alada, con lo 
que ambos casos vienen a caracterizar a dichos personajes dentro de su grado de maldad. Y si la propia simbología puede en muchas ocasiones apuntar a significados opuestos para un mismo elemento, como ocurre con el cisne y la mariposa, en «The Scarlet House» se muestran en numerosas ocasiones ambivalencias y cambios, de ahí que el Conde aparezca al principio del relato firmando sus cartas con una pluma de un pavo real y al final de la narración dicha pluma sea de un halcón. Dicho animal, mencionado en varias ocasiones a lo largo del cuento y que también se encuentra abriendo y cerrando la narración, al caer sobre su presa se puede asociar de manera fácil con la captura que sufrió la protagonista, para convertirse desde ese momento en un icono, en una imagen que queda en la memoria y que la propia narradora indica que es un modelo (2006b: 427).

Se puede seguir una intención similar en la utilización de los colores. Dentro de las distintas formas en las que Madame Schreck aparece ataviada, se la puede ver con un uniforme verde oliva, como si de un militar se tratase, para, poco después, aparecer vestida de rojo, color que la narradora identifica con la mujer (2006b: 424), no en vano dentro de su simbología está vinculado, entre otros aspectos, con la vida (CHEVALIER y GHEERBRANT, 2007: 888). Y es significativo que rápidamente el Conde la cubra con una bata azul, el más profundo de los colores que se pierde en lo indefinido, en una reacción relacionada con el espacio que ocupan. En cuanto a dicho espacio, al principio la narradora indica que la «Scarlet House» se parece a un hospital, porque allí curan las heridas que se hizo durante su traslado, por eso su color es blanco. Más tarde es identificada con un edificio que es granja y mansión al mismo tiempo y entonces su color es rojo, pero el color escarlata que le da nombre es una tonalidad del rojo, entre el carmesí y el grana, y todo ello vendría a apuntar de nuevo a las diferentes visiones o interpretaciones que se pueden tener sobre una misma realidad. Se trata, además, de uno de los colores que, dentro de su actual situación, aparece junto a la amable descripción de las flores de la casa de sus padres, donde se encuentran también el blanco y el rosa salmón de los geranios (2006b: 421).

Pero los recuerdos que va presentando la narradora no siempre se ofrecen de manera conectada, efecto provocado por las pseudomemorias que el Conde instala en ella dentro del caos que quiere provocar, un caos que ya gobierna en las ruinas gracias a las cartas del Tarot. El Tarot, debido al carácter azaroso en el que pueden aparecer las cartas y a que, desde una perspectiva científica no es posible conocer los hechos por métodos adivinatorios, no ofrece la misma credibilidad para todas las personas, de ahí que se le compare con el racional juego del ajedrez. De la misma forma que los príncipes medievales jugaban al ajedrez utilizando a sus vasallos como piezas, el Conde juega al Tarot de una forma peculiar en la que Madame Schreck sería la Papisa y el consejero sería obviamente el Loco, personaje que ya solo chilla y balbucea y casi ha olvidado cómo hablar, por lo que se encuentra cerca de esa indefinición que pretende el Conde para sus secuaces y prisioneros, y es que el Loco es el único arcano mayor que no tiene número en las cartas del Tarot. Por su parte, el propio Conde, que no aparece claramente vinculado con ningún arcano, es descrito en este punto por la narradora como un científico por la forma en la que enfoca el juego. Estos arcanos mayores, para completar el juego, fuerzan a participar a las prisioneras, que son los arcanos menores. Las vidas de estas mujeres se sitúan en una casa que es identificada ahora con un burdel en el que la memoria es la prostituta (2006b: 424), y se enmarcan 
dentro de este sistema en el que aparecen y desaparecen por el capricho de sus captores. En el juego del Tarot, la combinación de la simbología de sus figuras, la numerología y los colores hace que las posibilidades de interpretación de cada carta y de la relación de todas entre sí se multipliquen, por lo que se vuelve a insistir en este aspecto ya reseñado.

Aunque la numerología forme parte del Tarot también se puede encontrar en otros ámbitos como la cabalística. De tal manera que los 22 años que dice tener la protagonista es el mismo número de los arcanos mayores del Tarot, pero es además un número matemático, astrónomo y cabalístico: 22 son los axiomas sobre la voluntad humana en la teosofía (ALBAIGÉS, 2014: 95-96). Por otro lado, también tiene un recuerdo que parece claro de cuando tenía seis años, siendo este un número de completitud, al ser el primer perfecto y, por tanto, apuntar a la reunión y el equilibrio (ALBAIGÉS, 2014: 55). Pero, sobre todo, destaca la reiteración del número tres en este relato de Angela Carter. Se trata de un número que tiene una gran presencia en las divinidades de algunas religiones, la mitología y en algunos cuentos de hadas, donde es habitual que haya personajes que tengan tres hijos, como sucede con «La flor del lilo-va» o «Las tres bolitas de oro». En «The Scarlet House», la triada formada por el Conde, Madame Schreck y el Loco aparece enfrentada a la narradora y los padres de esta. El currículum del Conde consta de tres puntos: aprender a olvidar, olvidar cómo hablar y dejar de existir. Y para llevar a cabo este peculiar trivium ha instalado tres pseudomemorias en la mente de la protagonista con el objeto de que mezcle los tres tiempos (pasado, presente y futuro), lo que supondría, además, la implicación de que pasado y futuro son igual de ilusorios. Este ataque es combatido por la protagonista por medio de tres recuerdos mnemotécnicos constantes: el halcón, el hombre sin boca y los ojos sin rostros.

Cada uno de estos campos tiene su propio código o lenguaje, por lo que habría que cuestionarse por la importancia que se le da en este relato a la lengua en sí, sobre todo cuando el Conde es consciente de que es uno de los elementos que tiene que eliminar. Para ello cuenta con la colaboración de Madame Schreck, cuyo nombre señala diversas implicaciones. Mientras que la palabra francesa Madame es un tratamiento de cortesía para dirigirse a una mujer, el apellido es de origen alemán y de género masculino (der Schreck), que significa miedo, con lo que se complementan nacionalidades y géneros para presentarla como la encarnación de la fertilidad, de ahí que las prisioneras tengan que rendir homenaje a su sexo y que sea un personaje que suele ir acompañado de referencias sexuales en casi todas sus apariciones. Por tanto, es también el personaje que se encuentra más cerca del caos, entendiéndolo aquí como origen del universo, como se verá a continuación. En lo que se refiere al caos como ausencia de memoria y comunicación, Schreck puede evocar a to shriek, pues una de sus funciones es la de gritar para el Conde (GARCÍA BARRERA, 1999: 139-140). Además de lo indicado, hay que resaltar que, al final de «The Scarlet House», dentro de una de las reflexiones que está haciendo la narradora, después de un pequeño ejercicio etimológico llega a la conclusión de que tuvo que aprender latín en algún momento de su vida. Llama la atención que, desde ese momento hasta el ya próximo final del relato, aparezcan algunas palabras de raíz latina como ocurre con «elide», «concretisation», «declension», o que incluso se prefiera el uso de estos vocablos como «predicament» y «oubliette» (CARTER, 2006b: 427-28), en vez 
de emplear las palabras inglesas awkward y dungeon, respectivamente. Con lo que la utilización de los conocimientos que tiene la narradora sobre diferentes lenguas con las que puede estar familiarizada se presenta como un arma para mantener viva su memoria.

Ya por último habría que mencionar aquellos conceptos e ideas de la Antigüedad Clásica, algunos de ellos ya avanzados. Se acaba de mencionar el caos como elemento generador y primigenio, pues no puede haber orden si antes no hubo caos. Esta idea aparece ya en algunas cosmogonías griegas, como en Hesíodo. En cuanto a esa memoria que la narradora no quiere perder, dentro de una reflexión que hace al respecto, la presenta como la guía que ayuda a que no se pierda el camino, y lo ejemplifica con el personaje de Ariadna y la metáfora de tejer (2006b: 418). Siguiendo con este relato mítico cretense, el monstruo que se encuentra en el laberinto de la memoria es Madame Schreck, que es descrita de la siguiente forma: «[T]he Minotaur with the head of a woman and the orifice of a sow» (2006b: 422), con lo que vuelve a aparecer la referencia al cerdo como animal entrópico. Todo el proceso de eliminación de la memoria e imposición del ruido hace que las prisioneras, cuando están juntas de noche, lleven uno de sus dedos hacia la boca de una de las compañeras, como si quisieran asegurarse de que el hueco para el canal de comunicación continúe abierto, de ahí que la narradora se pregunta si no son ya sombras (2006b: 425). Pero habría que cuestionarse si no son sombras también las imágenes que la protagonista conserva del mundo exterior, como ocurre con los aullidos de los zorros o las dos versiones sobre la forma en las que fue capturada. En este sentido, es interesante la analogía con la alegoría de la caverna de Platón, que merece un apartado propio que se desarrollará más adelante.

Resulta razonable que el ser humano busque un sistema preexistente para explicar aquello que le es desconocido. Más lógico es que, teniendo en cuenta su situación, la narradora de «The Scarlet House» busque apoyo en diferentes campos que conoce. Quedaría por comprobar, por tanto, si la clave que le permite entender su posición está en la suma de todos estos conocimientos previamente adquiridos o si, además, se puede añadir algún otro.

\section{LA FILOSOFÍA DE LA HISTORIA}

Este apartado pretende comprobar de qué manera las diferentes ideas que tenía Angela Carter sobre la Historia encuentran acomodo dentro de las numerosas propuestas que se han dado en la filosofía de la Historia para explicar dicho fenómeno. Se comenzará por retomar las cuatro ideas apuntadas en el segundo apartado para luego analizar dicho rasgo de manera específica en las obras que centran este estudio. Puesto que se trata de un rasgo que ya se comentó en el tercer apartado para «The Lady of the House of Love», la mayoría de las referencias se harán aquí a «The Scarlet House», un texto con mayor grado de complejidad en el campo que se va a desarrollar, aunque también se añadirán los comentarios pertinentes a «The Lady of the House of Love» cuando sea oportuno.

La primera de las cuatro características comentadas en el segundo apartado apuntaba a la atención que Angela Carter pide para aquellos grupos marginales a los que la Historia no les ha dado la suficiente importancia. Se trata de una idea que se encuentra enfrentada a la de la historia total, originada en la Escuela de los Annales, fundada en 1929 por Lucien 
Febvre y Marc Bloch. En efecto, frente a esta concepción, que solo atendía a los grandes nombres, surgió la idea de plantear una historia individual en la que se le prestara atención a todas aquellas personas anónimas que, dentro de su vivir, también forman parte de la Historia y ayudan a construirla. Es un planteamiento que se encuentra en William Godwin (1756-1836), quien ya propuso que la historia individual aventaja a la general (2016: 462), y más tarde en el Construccionismo, donde se procura romper con una concepción estratificadora de la Historia para darle mayor relevancia a aquellas personas que habitualmente han sido excluidas de ella (DONNELLY y NORTON, 2011: 40). El segundo punto comentaba la difusa línea que separa la Historia de la ficción. En este sentido hay que recordar que el elemento ficticio se puede encontrar ya en algunas de las primeras manifestaciones historiográficas del mundo occidental. Más tarde, ya en los orígenes de la historiografía, Heródoto no busca la verdad en su obra sino que expone diversas noticias que le han llegado, incluso las que él personalmente cree como falsas ya que uno de los objetivos que busca Heródoto es luchar contra el tiempo y el olvido (GÓMEZ-LOBO, 1995: 4-6). El tercer aspecto se refería a la concepción de la Historia como palimpsesto. La Historia también se ha tratado de explicar por medio de metáforas o imágenes siendo el palimpsesto una de ellas. Debido a su impacto, y quizás también porque no deja de tener actualidad, resulta tentador relacionar la idea del palimpsesto con la de la reescritura orwelliana de la Historia, pero no se trata de la única implicación de esta imagen. Ya Thomas Carlyle (1795-1881) comentaba esta idea de una acumulación de narrativas que se proyectaría hacia una metanarrativa histórica (MCCAW, 2000: 83), lo que implicaría una profunda labor de interpretación y explicación. Y dentro de los numerosos materiales que se pueden encontrar está el folklore (BENEDUCE, 2017: 168), un elemento que ya se ha señalado en la producción de Angela Carter. Por último, se encuentra la memoria. La memoria y las historias, aunque son elementos distintos, más que oponerse entre sí se enlazan, son partes constitutivas la una de la otra y lo pueden ser en múltiples direcciones (LOWENTHAL, 1998: 273). Un ejemplo de ello es el peligro que supone la confusión del recuerdo con la imaginación, que proviene del hecho de que las memorias se pueden convertir en imágenes, algo que afecta al objetivo de fidelidad que caracteriza la búsqueda de la verdad (RICOEUR, 2006: 7). Pero la memoria también es sinónimo de imaginación, de forma que: «Thus, a personal memory transformed into an image can acquire historical status, and the images of popular culture have the capacity to affect personal memories» (STURKEN, 1997: 65-66). Por tanto, se encuentra de nuevo la situación en la que las esferas histórica y personal se influencian mutuamente en la construcción del discurso histórico, en un rasgo que ya se ha comentado en «The Scarlet House» con la imagen del halcón.

En efecto, algunas de estas ideas vuelven a aparecer en este relato de Angela Carter. De tal manera que la narradora indica que los borrados, sustituciones e imitaciones a los que es sometida hacen que su memoria ahora sea un palimpsesto de posibilidades y probabilidades (2006b: 424). Poco después de esta observación, recuenta el momento de su captura, que podría ser la de cualquiera de las otras prisioneras, por lo que dice experimentar que puede estar más cerca de «you all» (2006b: 425), con lo que estaría apuntando a una intención similar a la de la historia individual. Ya por último, también es consciente de que el halcón y el hombre sin boca y los ojos sin rostro pueden no contener rasgos de una memoria real. Son elementos inservibles pero con significado si pudiese recordar, de ahí 
que concluya, curiosamente utilizando el mismo concepto que Barthes, diciendo que son residuos (2006b: 426), pero, como ya se comentó, se trata de unos residuos que poseen la importancia que pueden tener los detalles por el significado que estos albergan.

Pero, además, se pueden encontrar otras referencias de nuevo vinculadas a la filosofía de la Historia que vendrían a completar esta perspectiva. A continuación, se comentarán algunas de ellas y se hará mención al trasfondo teórico que se puede seguir.

Una de las formas por las que se ha tratado de explicar la Historia ha sido por medio de imágenes. Una de ellas es la de las ruinas, imagen que también tiene seguimiento en la literatura y cuyo desarrollo alcanzó relevancia en Europa a partir del siglo XV. Siglos después, para Walter Benjamin (1892-1940), la ciudad, cuyo paradigma es París, hace posible vincular sus ruinas con la memoria, tratando de relacionar el pasado con el presente. Las piedras de los edificios hablan el lenguaje de los sueños, es como si la ciudad tuviera memoria (TONKISS, 2005: 120). A partir de aquí surge la reflexión sobre el pasado en el presente para comprobar hasta qué punto las ruinas pasadas se pueden repetir en la actualidad, o si bien el ser humano ha derivado su camino hacia otros senderos. En «The Scarlet House» es una de las primeras imágenes que aparece en el relato, junto con el halcón, y se muestra también como el resultado que el Conde quiere lograr cuando instaure el caos (2006b: 417). $\mathrm{Al}$ no presentarse un contacto directo con ellas, las ruinas son solo parte del recuerdo de la narradora y, a partir de ahí, un motivo de reflexión sobre el tiempo.

Otra de las imágenes que se han utilizado para explicar el fenómeno histórico es la del laberinto. Se trata de una estructura compleja en la que hay un caos planeado. Y es que el laberinto también establece un desafío familiar: encontrar el camino desde la entrada hasta el centro y volver desde ahí a la salida, un reto que se complica por los errores, las bifurcaciones, los giros, los caminos sin salida y en el que la labor es más compleja si, como sucede en el laberinto de Creta, hay un monstruo en el centro. Ya se comentó con anterioridad la referencia a la memoria por medio de la alusión al mito de Ariadna y el Minotauro en «The Scarlet House». Así, hay un momento en la narración en la que la protagonista compara su mente con un laberinto (2006b: 422). Luego, describe los tapices que decoran el vestíbulo del Conde de esta manera: «It's a maze of cells like the inside of a brain» (2006b: 423). Algo en lo que insiste más tarde para referirse a su estado mental. Al final del relato, vuelve a hacer una referencia al respecto cuando la narradora se compara con un conejo ubicado en las callejuelas de la memoria (427), con lo que remite de nuevo al halcón cazando a su presa. Pero esa percepción del laberinto depende de la posición que ocupe cada sujeto (Doob 1990: 1), algo que se refleja en este relato de Angela Carter en la manera en la que el personaje principal está experimentando su cautiverio y la forma en que lo vive el lector al llegarle la información por medio de trozos de diferentes relatos, con la cuestión subyacente del lugar en el que se situaría dicho lector.

La Historia también se ha tratado de explicar como un proceso marcado por un destino ya establecido. Como una forma de darle sentido a la existencia humana en el mundo, la actividad simbólica del pensamiento mítico apuntaba a una explicación total del origen del cosmos y del destino de los seres que lo habitan (BARASH, 2011: 330-331). No obstante, Platón lo veía de una manera distinta: «In the myth of Er in the Republic he shows 
individual souls choosing their own daimon, fate in life, before rebirth, but more usually the Greeks believed that one's fate was allotted» (HOWATSON, 2013: 182). Un pensamiento que suponía una gran diferencia con el planteamiento de los mitos ya que esta idea de Platón sobre la elección del destino implica una consciencia sobre la decisión que se está tomando y la relevancia posterior que va a tener para quien la toma y para los demás. Se trata de dos planteamientos que tuvieron seguimiento en los siglos posteriores, siendo Immanuel Kant (1724-1804) partidario de un destino insoslayable que el ser humano tiene que seguir, algo que apunta en el octavo principio de Ideas para una historia universal en clave cosmopolita (1784), mientras que para Ralph Waldo Emerson (1803-1882) la libertad y el destino no son términos contrapuestos sino que están ligados puesto que el ser humano también posee la libertad de elegir y aceptar ese destino (RICHARDSON, 1995: 502). En «The Lady of the House of Love», la Condesa trata de evitar el destino que le han marcado sus antepasados por medio de los arcanos del Tarot (2006a: 196). La carta de Los Enamorados, que nunca había aparecido, marca un camino diferente en el que se encuentra el amor, pero la posible relación amorosa con el soldado supondría aceptar otro tipo de convención social y literaria. Al final del relato, junto al cuerpo de la Condesa se encuentran las cartas del Tarot, que están tan gastadas que no se ven las imágenes, ya no hay destino porque ella ha decidido al respecto. Es algo que también tendrá que hacer el joven inglés, del que se dice de manera irónica que la historia ya ha preparado un destino especial y ejemplar a su generación en las trincheras de Francia. En cuanto a «The Scarlet House» se llega a comentar que el momento de la captura de estas mujeres que se encuentran ahora prisioneras ha marcado cuál va a ser su destino. En el caso concreto de la protagonista, habla de su propio destino cuando desciende del carruaje e intuye lo que le puede suceder desde ese momento. Aunque no es una idea que aparezca siempre con nitidez, ya que en su recuerdo sobre el halcón confiesa que entonces no era consciente de cuál podía ser su destino. En la resolución se puede comprobar si las protagonistas de estas dos narraciones han cambiado su percepción sobre lo que para ella significa dicho concepto.

Otro enfoque que ha buscado explicar la Historia ha sido por medio de la experimentación de la misma de modo fenomenológico. En este campo hay que destacar la aportación de Maurice Merleau-Ponty (1908-1961), que destacó el papel que juega el cuerpo en la experimentación fenomenológica y cómo está vinculado a la memoria (2012: 96 y ss.). En lo que se refiere a la materia histórica, dicho filósofo francés radicalizó la propuesta de Edmund Husserl (1859-1938) y, en ese sentido, se ha indicado lo siguiente: «[D]emostró que las esencias no son ahistóricas, sino el resultado de la sedimentación de intuiciones y conocimientos empíricos» (GARCÍA CANCLINI, 1979: 11). Y si existen intuiciones, por un lado, y datos empíricos, por otro, es porque ambos elementos forman partes constitutivas de la Historia, por lo que se justifica un acercamiento que vaya más allá de la exégesis, el análisis y la crítica y que busque una comprensión total donde se consideren estados de ánimo, de consciencia y de aquellos aspectos que ayuden a entender la Historia como un fenómeno global, dado su carácter inabarcable. Por tanto, la literatura se presenta como un medio ideal para poder trasladar esta fusión de elementos donde, en muchas ocasiones, los sentidos cobran una destacada importancia. En «The Lady of the House of Love», la Condesa advierte la cercanía de un inglés por su sentido del olfato, un hecho que la alegra puesto que lleva varios días sin poder saborear a ninguna víctima. Cuando se encuentra con él, siendo 
este una figura solar, protege su vista por medio de unas gafas de cristales oscuros. Finalmente, no puede tomarlo de la mano para llevarlo a su dormitorio, como suele hacer con los hombres que le traen, sino que es él quien la toca en la inversión de la relación vampiro-humano queriendo sanar la herida. Es la forma peculiar en la que se produce el beso entre los protagonistas, como en «La bella durmiente», y que hará despertar a la Condesa a una nueva realidad. El soldado también experimenta el nuevo mundo que supone el castillo para él por medio de todos sus sentidos: por la comida que le preparan, oyendo el canto de la alondra, aclimatando su visión a la oscuridad en la que se encuentra la habitación de la Condesa, el tacto y, finalmente, el olor de la rosa que inunda los barracones militares (2006a: 209), con lo que el llamamiento a reconsiderar la aceptación del citado destino sería tanto en el nivel inteligible como en el sensible. Por eso también, cuando la protagonista de «The Scarlet House» logra refutar la validez de la pseudomemoria del tren y el carruaje lo hace en base a que el material que la compone tiene cierto sabor literario, de ahí que llegue a la conclusión de que tiene olor a pseudomemoria. El mismo sentido está presente cuando recuerda la fragancia de las flores de su casa paterna (2006b: 421). Es tan consciente de la validez de esta forma de experimentar su propia historia que cuando trata de recordar al halcón se dice a sí misma que se debe concentrar en experiencias físicas.

Aunque ya se hizo referencia con anterioridad a la relación entre la Historia y la ficción, se hace necesario, llegado este punto, retomar este aspecto pero considerándolo dentro de la postmodernidad, etapa donde se encuadra la obra de Angela Carter. En este ámbito resulta casi inevitable mencionar a Hayden White (1928-2018), quien recela de la idea de alcanzar una historia objetiva puesto que si el historiador forma parte de los sucesos históricos que narra toma partido de ellos, y si no fue así le falta la experiencia de haberlos vivido (WHITE, 1986: 81), una idea que ya se encuentra en Metahistory (1973), donde dicho autor propone un acercamiento a la Historia en base a tropos, ya que en el origen del discurso histórico se encuentra la memoria, que no puede recordarlo todo. Ante la imposibilidad de acceder al pasado histórico y al hecho de que la historiografía expone los sucesos de forma lineal, como las propias narraciones mitológicas y folklóricas, se acepta que un mismo relato pueda tener distintas lecturas desde diferentes enfoques, por lo que las interpretaciones pueden ser infinitas (JENKINS, 1991: 11). Se trata de dos disciplinas que se encuentran unidas de tal manera que se interrogan mutuamente (LACAPRA, 2013: 12). Ante esta situación, se propone la equiparación del discurso histórico con el literario, puesto que se muestran ligados desde sus orígenes y solo quedaría una aproximación literaria a la Historia ya que ambos discursos pasarían a tener la misma validez.

Como se comentó con anterioridad, la Condesa de «The Lady of the House of Love» no desea vivir aislada de la realidad pero tampoco se siente atraída por una ausencia de imaginación. Entre ambos extremos busca un punto intermedio, metahistórico. Por su parte, en la resolución de «The Scarlet House» la protagonista acaba venciendo cuando acepta que el caos está en el origen de la memoria, como lo está también en el origen del universo, y admite que en la refutación de la Historia está su liberación cuando es consciente de que no va a salir de la mazmorra, o laberinto, en el que se encuentra, que su visión no es completa ni lo va a ser pero, al mismo tiempo, necesita tener presente todo esto por medio de su recuerdo mnemotécnico. Tanto el cochero de la segunda memoria como 
los motoristas no tienen boca para poder expresarse porque ya están atrapados en el mundo del Conde y la protagonista quiere evitar ser una nueva presa, de ahí que afirma al final del relato: «When I perceived I'd organised these disparate elements into a grid, or system of connections, I felt for the first time I entered the obscure portals of the Scarlet House, a flood of joy» (2006b: 428). Ella se describía al principio de la narración contemplando el paisaje como una naturalista (417), y es que su capacidad de observación la ha convertido en una naturalista de la Historia que ha sistematizado elementos inconexos entre sí y por eso ahora percibe la casa de una nueva forma, puesto que ha entendido que es el lugar en el que va a estar siempre, por eso escribe al final desde la perspectiva metahistórica que ha alcanzado. Aunque existan rasgos que permitan descartar la verosimilitud de ciertas partes de las pseudomemorias, la protagonista acepta la utilidad de aquellos elementos (residuos) que le ofrecen mayor grado de credibilidad para darle a todas las memorias la misma validez. Es la forma que tiene para controlar ahora el juego y, como ella misma ejemplifica, dejar de ser marioneta para ser ahora marionetista. Este hallazgo metahistórico se podría comparar con el descubrimiento de algún mensaje cifrado que permanece ignoto para los no iniciados en un campo, como sucede con los adornos («patterns») cabalísticos en las chaquetas de los motoristas.

\section{LA CAVERNA DE PLATÓN}

La aproximación a estas dos narraciones de Angela Carter que centran el presente estudio no quedaría completa si el análisis de personajes, las relaciones entre ellos, los temas, el contexto y las alusiones no fueran acompañados de una reflexión sobre el lugar en el que se desarrolla la acción que, en este caso, aparece en el título de los dos relatos. Tanto «The Lady of the House of Love» como «The Scarlet House» tienen otros aspectos en común como el vampirismo, el Tarot o el destino y, en lo que se refiere a su configuración dentro de la literatura postmoderna, son relatos abundantes en referencias intertextuales. En este apartado se comentarán algunas vinculadas sobre todo con la Antigüedad Clásica, haciendo especial hincapié en la caverna de Platón. Se trata de una alegoría que viene a hablar de la posición del ser humano frente al conocimiento y la relación existente entre el mundo sensible y el inteligible y que, una vez más, ha tenido diferentes interpretaciones. En lo que se refiere a su significación histórica e implicaciones políticas apunta a la necesidad de asegurar una estabilidad por medio de una desigualdad entre los individuos de una comunidad a la luz de una autoridad filosófica (BARASH, 2011: 336).

Dentro de esa intertextualidad ya se ha comentado en «The Lady of the House of Love» la referencia a «La bella durmiente», aunque también se han señalado obras como Dracula, «The Lady of Shalott» o Great Expectations, entre otras (PÉREZ GIL, 2016: 512). También habría que destacar las alusiones en las que no todas las referencias son literarias. Dentro de las diferentes formas en las que se describe a la Condesa se dice de ella al principio del relato que es «a girl who is both death and the maiden» (2006a: 195), con lo que se está apuntando al cuarteto de cuerda no 14 de Franz Schubert, conocido de esta manera (Der Tod und das Mädchen en alemán) y donde se muestran las reacciones de una joven moribunda ante la proximidad del fin de su vida. Además de todo 
ello, es de reseñar entre otro de sus posibles intertextos la historia mitológica de Eros y Psique, que acabaría recogiendo Apuleyo en sus Metamorfosis, no solo por la significación de los lugares en los que se desarrolla la trama sino también por la conexión de algunos rasgos de la narración con los cuentos de hadas y la literatura gótica (HAGOPIAN, 2007: 52). En ambos relatos, hay un deslumbramiento por parte del personaje femenino cuando conoce la identidad de su amado, algo que sucede en el lugar que ellas habitan: el palacio de Psique y el castillo de la Condesa. En el relato de Carter, la referencia se completa con la vinculación que se puede establecer con una de las más célebres aportaciones en la historia de la filosofía: la alegoría de la caverna de Platón. Son varias las referencias que existen a la caverna en esta narración: al comienzo del relato, en la descripción de la Condesa, se dice que su voz «is filled with distant sonorities, like reverberations in a cave», y que ella misma es «a cave full of echoes» (2006a: 195); cuando el joven entra en el castillo se menciona de dicha morada su «lightless and cavernous interior» (2006b: 200). Esta descripción hace que el castillo en el que se encuentra la Condesa, el mismo que habitaron sus antepasados, se presenta como el lugar ideal para que ella repita actos, ideas y palabras, como sucede en este último caso tanto con las iteraciones como con el uso de rimas. Pérez Gil también advierte esta vinculación con Platón pero su visión viene a ahondar sobre todo en las interpretaciones feministas (2016: 512 y ss.). Así, la Condesa estaría recluida en una caverna conceptual donde las imágenes de la realidad que ella conoce son solo sombras: nunca ha visto un león pero lo puede imaginar, nunca vio el sol pero lo conoce por las cartas del Tarot (2006a: 206). La referencia aquí es «The Lady of Shalott», tanto por la percepción deformada de la realidad como por los deseos de ruptura. De igual forma, las ideas que tiene inculcadas sobre su modo de actuar son las que una sociedad patriarcal ha querido mostrarle. Entonces, el soldado es presentado como un héroe solar, que tradicionalmente trasciende el lado femenino oscuro y misterioso y que vendría a iluminarla, pero en realidad ambos son productos culturales cuyas identidades han sido construidas por otros; son tan diferentes como el día y la noche (BUCHEL, 2004: 28-29). De ahí que la propuesta que le ofrece el soldado no es la que ella esperaba y por eso no la sigue, con lo que la liberación final que alcanza de este mundo opresor masculino es de tipo cultural y discursivo, al no seguir la pauta que se espera de ella ni por parte de sus antepasados ni por el joven que se supone que la debe liberar.

Si se sigue dicha alegoría, pero ya dentro de la interpretación histórica que aquí se propone, sería posible argumentar que la Condesa desea salir del mundo de fantasía que siempre la ha rodeado, pero cuando descubre la realidad de la historia tampoco la acepta como alternativa, de ahí que busque un camino metahistórico propio en el que fantasía y realidad convivan. El sangrado final, vinculado con la pérdida de inocencia, también habría que entenderlo como un paso en este proceso de madurez cognitiva. La alondra, trasunto de la Condesa, reacciona de la siguiente manera cuando es liberada por el soldado: «At first, it exhibited the reluctance for the sky of a long-caged thing, but, when he tossed it up on to the currents of the air, it spread its wings and was up and away into the clear blue bowl of the heavens; he watched its trajectory with a lift of joy in his heart» (2006a: 208). Con lo que no muere víctima de las alimañas que rodean al castillo sino que, tras las dudas iniciales al estar en un nuevo espacio, logra levantar el vuelo. Si la Condesa se hubiese convertido en humana estaría viva y habría adquirido tal forma, que es lo que el 
joven desea en su ingenuidad llegando a pensar todo lo que haría con ella: llevarla a una clínica, a un oculista, a un dentista y a la manicura, lo que supondría seguir un nuevo dictado desde los puntos de vista androcéntrico, discursivo e histórico. Pero el espacio que la Condesa desea no es este ni tampoco el castillo. Una vez familiarizada con un mínimo de información histórica, la Condesa vuela, cualidad habitualmente atribuida a la imaginación, por sí misma. Ya ni siquiera es un murciélago, uno de los animales en los que se pueden transformar los vampiros, sino que se ha convertido en un espíritu libre, de ahí que no haya más presencia de ella al final de la narración más allá de su cuerpo sin vida y la plasmación de sus últimos pensamientos. Dentro de todo este entramado alusivo, la alondra («lark») se puede vincular con el poema «To a Skylark» de Shelley (HENNARD, 2011: 3), que comienza con una estrofa en la que la voz lírica la saluda para decirle a continuación: «pourest thy full heart / in profuse strains of unpremeditated art» (SHELLEY, 2002: 469), unos versos que apuntan a las ideas de individualidad y libertad, por eso esta voz lírica acaba pidiéndole a la alondra que le enseñe su canción, algo que sería un don incalculable para un poeta porque este escribiría versos que los lectores leerían con el mismo placer con el que él ahora escucha el canto de la alondra (SHAWA, 2015: 127). Resulta lógico, por tanto, que la figura del vampiro sea uno de los elementos recurrentes en la obra de Angela Carter ya que se trata de seres que son simultáneamente bestias y humanos, al no estar ni vivos ni muertos están en la frontera entre ambos, en su origen con la vinculación con Vlad el Empalador se combina la historia con la ficción (BOTELHO, 2016: 293-294), de ahí que la Condesa encuentre su espacio en un plano diferente a los dos que se le ofrecen. De igual modo, la rosa que se lleva el soldado también presenta un carácter ambivalente y contradictorio (2006a: 209), lo que se pone en relación con el destino histórico que le espera al joven si sigue los pasos que ya le han marcado, un destino que no parece ser mucho mejor que el de ser devorado por un vampiro. La rosa, por tanto, es un recordatorio del encuentro que han tenido. En una nueva vuelta al patrón, es la Condesa quien lo ayuda a él ahora ya que, por medio de este detalle, parece invitar al joven a que la siga en ese camino propio que ella ya ha emprendido.

Por su parte, la protagonista de «The Scarlet House» desea su liberación para alcanzar una nueva realidad que le dé la clave de su actual estado cognitivo. Esta liberación no es únicamente individual. En el relato, la narradora muestra su solidaridad con las otras prisioneras con las que comparte deseos de libertad, pero también de comunicación, estando ambas ideas vinculadas, por añadidura, con los posibles lectores. Es aquí donde emerge la analogía con la caverna de Platón, donde una de sus posibles interpretaciones es en clave política con el prisionero liberando y dirigiendo a sus compañeros, que todavía se encuentran encadenados, hacia la luz. Estos se burlarían de él y pensarían que sus ojos han quedado cegados por la luz solar. En el caso de la protagonista de «The Scarlet House», las incongruencias que muestra desde un primer momento y la mezcla de fragmentos no ordenados de tres pseudomemorias pueden hacer pensar al lector que está desorientada, que no es una narradora fiable. Al principio, el lector puede que no sea consciente de su posición en la Historia, o puede no considerar esta intención en el relato, pero el giro final lo sitúa dentro del laberinto de la Historia, en un lugar similar al de las prisioneras. En este punto, la experiencia de la narradora, que ya la ha transformado, surge para ofrecer una revelación en clave metahistórica. 


\section{CONCLUSIÓN}

En la obra de Angela Carter, que se sitúa en la postmodernidad, se pueden encontrar dos destacados rasgos estilísticos como son la intertextualidad y la reescritura de textos. En cuanto a la temática, aunque el feminismo es una preocupación patente, el presente estudio quiere llamar la atención sobre la presencia que tiene la Historia en la producción de la citada autora. En este sentido, se han destacado la defensa de una historia individual que incluya a todos los miembros de la comunidad como partícipes de la Historia, las conexiones entre la Historia y la ficción, el palimpsesto como imagen de las posibles reescrituras que puede experimentar la historiografía y las diferentes interpretaciones que puede recibir un texto y, por último, la importancia de la memoria en el discurso histórico. Teniendo en cuenta todo ello, se propone un punto de vista alternativo de sus relatos «The Lady of the House of Love» $\mathrm{y}$ «The Scarlet House» desde la filosofía de la Historia, donde hay aspectos de dicha disciplina que tienen vinculación con otras obras de la misma autora mientras que otros cobran una especial significación en dichas narraciones.

Además, las protagonistas de estos relatos se familiarizan con la Historia de manera fenomenológica, siendo esta una de las formas por las que tratan de evitar un destino marcado por otros que ellas no desean seguir. Finalmente, la Condesa, alcanzando un camino propio, y la narradora de «The Scarlet House», ampliando su perspectiva epistemológica, logran interpretar la realidad que las rodea de manera metahistórica, algo que consiguen gracias a una revelación. Dicha epifanía hace que estos personajes femeninos tomen una decisión sobre el lugar de reclusión en el que se encuentran, que se puede vincular con la caverna de la alegoría de Platón en tanto que en dicho espacio se proyectan imágenes y conceptos que no guardan una relación fidedigna con la realidad y sobre las que las protagonistas tienen que tomar una decisión.

Esta decisión no queda solo como un deseo de trascendencia o salvación personal. Al principio de la narración de «The Lady of the House of Love», antes de la aparición del soldado, se utiliza la segunda persona y se dice sobre el ama de llaves: «She will invite you with smiles and gestures; you will follow her» (2006a: 197). Y poco después se insistirá en esa idea al decir: «If you stop too long beside the giggling fountain, you will be led by the hand to the Countess's larder» (2006a: 198), con lo que hay una identificación del próximo visitante desavisado al castillo con el lector. Por ello, la rosa como invitación a desafiar el destino no solo afecta al soldado y sus compañeros de barracón, e idéntica reflexión es aplicable al deseo de aprendizaje de Shelley en cuanto a la canción que canta la alondra. De igual modo, la protagonista de «The Scarlet House» comparte con los lectores el descubrimiento que ha alcanzado al final de su narración para desencadenarlos y, al mismo tiempo, estaría arrojando luz sobre la situación en la que estos se encuentran, que no parece ser muy diferente de la del resto de las prisioneras del relato.

Por todo ello, habría que considerar a la filosofía de la Historia como otro posible campo de conocimiento dentro del complejo entramado de modelos presentado y, en consecuencia, la pertinencia de interpretar «The Lady of the House of Love» $\mathrm{y}$ «The Scarlet House» desde una óptica metahistórica que, con la ayuda de la alegoría de la caverna de Platón, invitaría a alcanzar un camino propio y un mayor grado epistemológico a todo aquel que se acerque a la lectura de estas narraciones. 


\section{REFERENCIAS BIBLIOGRÁFICAS}

Albaigés, J. M. (2014): El numeronomicón. Diccionario de números, sus propiedades matemáticas, tradición histórica y simbolismo, Madrid, Tébar Flores.

Barash, J. A. (2011): «Myth in History, Philosophy of History as Myth: On the Ambivalence of Hans Blumenberg's Interpretation of Ernst Cassirer's Theory of Myth», History and Theory, 50, pp. 328-340.

Bauman, Z. (1988): «Sociology and Postmodernity», The Sociological Review, 36.4, pp. 790-813.

Beneduce, R. (2017): «History as Palimpsest. Notes on Subalternity, Alienation, and Domination in Gramsci, De Martino and Fanon», International Gramsci Journal, 2.3, pp. 134-173.

Berni, C. (1997): «Taking an Axe to History: The Historical Lizzie Borden and the Postmodern Historiography of Angela Carter», Clio, 27.1, pp. 29-55.

Botelho, I. (2016): «Destroying and Creating Identity: Vampires, Chaos and Society in Angela Carter's 'The Scarlet House'», Dracula and the Gothic in Literature, Pop Culture and the Arts, ed. I. Ermida, Leiden, Brill Rodopi, pp. 293-308.

Buchel, M. (2004): «The Fortunate Fall: Escape from the Realm of the Eternal Feminine in Angela Carter's 'The Lady of the House of Love'», English Academy Review, 21.1, pp. 22-35.

Carter, A. (1985): «The Company of Angela Carter: An Interview», Marxism Today, pp. 20-22.

- (2001): The Sadeian Woman, Londres, Penguin.

— ED. (2005): Angela Carter's Book of Fairy Tales, Londres, Virago.

- (2006a): «The Lady of the House of Love». Burning Your Boats: Collected Short Stories, Londres, Vintage, pp. 195-209.

— (2006b): «The Scarlet House». Burning Your Boats: Collected Short Stories, Londres, Vintage, pp. 417-428.

— (2013): «Notes from the Front Line», Shaking a Leg: Collected Journalism and Writings, A. Carter, Londres, Vintage, pp. 45-53.

Chevalier, J. y Gheerbrant, A. (2007): Diccionario de los símbolos, trad. Manuel Silvar y Arturo Rodríguez, Barcelona, Herder.

Donnelly, M. y Norton, C. (2011): Doing History, Londres, Routledge.

Doob, P. R. (1990): The Idea of the Labyrinth from Classical Antiquity Through the Middle Ages, Ithaca, Cornell University Press.

Filimon, E. C. (2014): Heterotopia in Angela Carter's Fiction: World in Collision, Hamburgo, Anchor Academic Publishing.

García Barrera, I. (1999): «Caos y (seudo-)memoria(-s) en 'The Scarlet House' de Angela Carter», Philologia Hispalensis, 13.2, pp. 139-145.

García CANClini, N. (1979): Epistemología e historia. La dialéctica entre sujeto y estructura en Merleau-Ponty, México, UNAM.

Godwin, W. (2016): Mandeville, ed. T. Rajan, Peterborough, Broadview Press.

Gómez-Lobo, A. (1995): «Las intenciones de Herodoto», Estudios Públicos, 59, pp. 1-16.

Hagopian, K. A. (2007): «Apuleius and Gothic Narrative in Carter's 'The Lady of the House of Love'», The Explicator, 66.1, pp. 52-55.

Hennard Dutheil de la Rochère, M. (2011): «Conjuring the Curse of Repetition or 'Sleeping Beauty' Revamped: Angela Carter's Vampirella and 'The Lady of the House of Love'», Études de Lettres, 3-4, pp. 1-15.

- (2013) Reading, Translating, Rewriting: Angela Carter's Translation Poetics, Detroit, Wayne State University Press.

Howatson, M. C., ED. (2013): Oxford Companion to Classical Literature, Oxford, Oxford University Press. 
Hutcheon, L. (2004): A Poetics of Postmodernism: History, Theory, Fiction, Nueva York, Routledge.

Jameson, F. (2002): The Political Unconscious: Narrative as a Socially Symbolic Act, Londres, Routledge Classics.

Jenkins, K. (1991): Rethinking History, Londres y Nueva York, Routledge.

LaCAPra, D. (20I3): History, Literature, Critical Theory, Ithaca, Cornell University Press.

Lowenthal, D. (1998): El pasado es un país extraño, trad. Pedro Andrés Piedras Monroy, Madrid, Akal.

McCAw, N. (2000): George Eliot and Victorian Historiography: Imagining the National Past, Basingstoke, Palgrave MacMillan.

MARIÑo FerRo, J. R. (1996): El simbolismo animal: creencias y significados en la cultura occidental, Madrid, Encuentro.

Merleau-Ponty, M. (2012): Phenomenology of Perception, trad. D. A. Landes, Londres, Routledge.

Mulvey-Roberts, M. (2016): «The Female Gothic Body», Women and the Gothic. An Edinburgh Companion, eds. A. Horner y S. Zlosnik, Edimburgo, Edinburgh University Press, pp. 106-119.

Okunata, Y. (2019): Angela Carter's Critique of Her Contemporary World: Politics, History, and Mortality, Londres, Birkbeck University of London, http://bbktheses.da.ulcc.ac.uk/442/1/cp_PhD_Thesis.pdf, acceso 04-12-2019.

Paul, H. (2011): Hayden White. The Historical Imagination, Cambridge, Polity Press.

Pérez Gil, M. M. (1996): La subversión del poder en Angela Carter, Las Palmas de Gran Canaria, Universidad de Las Palmas de Gran Canaria.

- (2016): «A Vampire in Plato's Cave: Mimesis, Anamorphosis, and Simulacra in Angela Carter's 'The Lady of the House of Love'», Critique: Studies in Contemporary Fiction, 57.5, pp. 512-520.

Richardson, R. D. (1995): Emerson: The Mind on Fire, Berkeley, University of California Press.

Ricoeur, P. (1988): Time and Narrative, vol. 1, trad. Kathleen Blamey y David Pellauer, Chicago, University of Chicago Press.

- (2006): Memory, History, Forgetting, trad. Kathleen Blamey y David Pellauer, Chicago, University of Chicago Press.

Rodríguez Salas, G. (2008) «Femininity and Vampirism as a Close Circuit: «The Lady of the House of Love» by Angela Carter», Sites of Female Terror. En torno a la mujer y el terror, eds. A. Antón-Pacheco et al., Navarra, Editorial Aranzadi, pp. 121-128.

Sempruch, J. (2008): Fantasies of Gender and the Witch in Feminist Theory and Literature, West Lafayette, Purdue University Press.

ShawA, W. (2015): «Stylistic Analysis of the Poem 'To a Skylark' by P.B. Shelley», IOSR Journal of Humanities and Social Sciences, 20.3, pp. 124-137.

Shelley, P. B. (2002): «To a Skylark», The Selected Poetry and Prose of Shelley, Ware, Wordsworth, pp. 469-472.

Sмiтн, B. J. (I998): The Gender of History: Men, Women, and Historical Practice, Cambridge, Harvard University Press.

Sturken, M. (1997): «Reenactment, Fantasy, and the Paranoia of History: Oliver Stone's Docudramas», History and Theory, 36.4, pp. 64-79.

Tonkiss, F. (2005): Space, the City and Social Theory: Social Relations and Urban Forms, Cambridge, Polity Press.

Vlitos, P. (2017): «'See! The Angel of Death!': Lizzie Borden, Angela Carter and l'effet de reel», Textual Practice, 31.7, pp. 1399-1416.

White, H. (1986): Tropics of Discourse: Essays in Cultural Criticism, Baltimore, John Hopkins University Press. 